\title{
Evolution is opportunistic, not directional
}

In 3 recent article published in Bioscience, Timothy Shanahan (2000) argues, among other things, that evolution is progressive, directional, and embodies improvement. However, empirical evidence from a vast array of organisms that display evolutionary loss of a number of phetonotypic characters present in their ancestors contra. dicts such assertions. Furthermore, the usc of vague terms reintroduced in Shanahan's article to define or describe cvolution in lieu of standard terminology currencly used in biology will result in confusion rather than in clarification of ideas.

A past example of what Shanahan is trying to do was the incorporation of the idea of "regressive evolution." Although this term was initially used by Lamarck (1809), it was not popularized until the beginning of the 20th century by students of cave, deep-sea, and parasicic organisms. Most of the species in those categories are characterized by the loss or reduction of a number of phenotypic characteristics such as, for example, eyes and pigmentation. Thus, these organisms became a paradigm for those who believe that evolution was in fact progressive and had a direction, a direction aimed at "improving" the organism as reflected in its structural complexity (Romero 1985).

Yer a closer look at the processes and common characteristics of these examples of regressive evolution leads us to believe that thcre is neither a direction in which to regress nor a special mechanism involved in the evolutionary parterns associated with them. In fact, this phenomenon can be explained by nondirectional mechanisms that take place at any level of the organic evolution.

Among the hypogean (caye) fauna, for example, we find thousands of spccies of troglobitic (obligatory cave) organisms characterized by the lack of cycs and pigmentation. The loss of these phenotypic features can be easily associated with a fundamental difference between their environment and that of most other animals: troglobires live in permanent darkness. Absent a selective pressure that favors the maintenance of light-related fearures such as eyes and pigmenlation, those fentures are lost through time. However, this trend is not as simple as it appears. Some of these organisms show a phenotypic reduction in some features, whereas others show an enhancement of some nonvisual sensory systems. Thus, these organisms seem to respond not to a particular trend, which would characterize regressive evolution, bul rather to the specifics of each environmental conditions in which they have evolved (Sket 1985).

To explain the more generalized trends of blindness and depigmentation, we do not need to look for novel or exceptionally rare explanations or terms. Troglobites are a perfect example of convergent evolution, a standard evolutionary phenomenon explained by natural selection. What happens is that convergent evolution remains onc of the most overlooked evolutionary phenomenon, and has yet to be subjected to a single synthesis (Conway Morris 1998).

Shanahan argues that "disagreements about evolutionary progress can probably be minimized (although nor eliminated completely) by specifying as precisely as possible the property or set of propertics at issue and the relevant comparison class (i.e., organisms in the same or different lineages)" (p. 456), but this is precisely the problem: Convergent

Lotrers to the Edltor
BioScience
Attn: Editor-in-Chief
1444 Eye St., NW Sujtc 200
Washington, DC 20005
The staff of BioScience reserves the right to
edir lettcrs for length or clarity without
notifying the suthor. Letters are published as
space becomes available.

evolution is an equal-opportunity mechanism that acts regardless of lineages. After all, troglomorphic organisms rep. resent a vast array of species belonging to lineages ranging from arthropod and nonarthropod invertebrates to vertebrates.

Shanahan also argues that "there may be a passive urend toward increasing complexity, not because complexity is better but just because if the organisms in a lineage begin as very simple creatures, they are more likely to evolve in one direction (e.g., toward increasing complexity) than the other" (p. 457). Yet thousands of examples not only from cave organisms but also from endoparasites, deep-sea animais (including organisms inhabiting deep-sea vents), underground mammals, and lightless insects and birds from islands argue otherwise. These organisms have undergone structural simplification in response to environmental constraints.

As an example of progressive evolution, Shanahan writes that "eyes have undergonc progressive cvolution from simple pinholc camera-lype cyes to the complex eye of the hawk" (p. 458). Yet blindness or reduction of the visual apparatus can be observed not only among the organisms mentioned above but also cven among estaceans that live in the murky water of some rivers.

To assign to evolution the property progressive is at best confusing and at worst a vestigial, neo-I amarckian notion of what evolution is all about. After all, the initial proponents of progressive evolution and rcgressive evolution have becn closely associated with the neoLamarckian movement in both North America and continental Europe, which lasted until the modern synthesis was accepted (and lasted sven longer in France). According to the Oxford English Dictionary, progression means the action of stepping or moving forward or onward. The question is, "Forward to where?" Sharahan seems to indicate that 
such movement is toward "improvement." For years we have used the term increased firness in biology, a welldefined and closely argued evolutionary concept that clearly states what we mean in terms of chances for survival. We do not need vague new terms that incorporate philosophical notions lacking empirical evidence such as orthogenesis (directionality) and smacking of neoLamaxckism.

Although classical definitions of cvolution have gravitated from the Darwinian notion of "descent with modification" to the neo-Darwinian concept of "changes in gene frequency," perhaps one of the most apt descriptions of evolution was given by Dobzhansky (1970), who wrotc that evolution is opportunistic, as biodiversity on Earth exemplifies. Unlike progressionism, opportunism is a well-established concept in ecology, easy to understand and to test experimentally.

\section{ALDEMARO ROMERO \\ Department of Biology and Envitonmental Studies Macalester College St. Paul, MN 55105}

\section{References cited}

Conway Morris S. 1998. The Crucible of Creacion The Burguess Shale and the Rise of Animals. Oxford (UK): Oxrord University Press.

Dobzhansky T. 1970. Generics of the Evolutionary

Process. Now York: Columbia University Press.

Lansarek IB. 1809. Plsilosophie Zoologiquac Hugh Elliot, trans. Londion: Macmillan.

Romero A. Can Evolution Regtess? Natrional Speleological Sociecy Bulletin 47: 86-86.

Sker B. 1985. Why All Cave Animals Do Nor Look Alike[em] A Discussion of the Adaptive Value of Reducion Processes

Shanahan I. 2000. Evolutionnry Progress? BioScience 50: 451-459.

\section{RESPONSE FROM \\ SHANAHAN:}

In my essay "Evolutionary Progress?" (BioSciance 50: 451-459), I suggested that "the debatc about evolutionary progress might have been all right once, but it has gone ou too long." Evidently some biologists feel otherwise.

Dr. Romero contrasts "evolution as opportunistic" with "evolution as di-

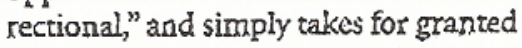
that the first description precludes the sccond. But one of the aims of my essay was to move thinking about evolutionary progress past such simplistic dichotomies by asking what precisely is required for cvolurion to be directional (or progressive, or both), and whethet the satisfaction of these requirements might be consistent with the agreedupon opportunistic character of natural selection. One way in which evolution could be both opportunistic and directional, I suggested, is if morc opportunities for adaptive advance exist in one direction than in another (Maynard Smith 1970). How often this condition is satisfied is an interesting question to be answered through theoretical and empirical investigation, not by dogmalic pronouncements.

Romero complains that I claim "evo. Jution is progressive, directional, and embodies improvement." If only life were that simple. (And I do mean life.) As I argued in my essay, concepts such as progressive, directional, and improvement, taken without careful qualification, are simply too blunt to provide any insight into the evolutionary process. He also complains that terms like progressive and improvement are vague and confusing. Indeed they are, which is why I devoted considerable space in my essay to disambiguating thern. But then most genuinely interesting concepts are like that. If he really thinks that "Gitness" is by contrast a well-defined concept in evolutionary biology (as distinct from being eminently useful, which is a quire different matter), I ean only refer him to any of the serious discussions of this term, which clearly dicmonstrate otherwise (e.g., Dawkins 1999).

In his letrer, Romero discourses at length on the fascinating features of cave organisms, his area of specialization, along with other organismsthat have undergone structural simplification, apparently unaware that the points he makes have no bearing on my essay's argument. of course there are innumcr-able cases of "regressive evolution." Every biologist since Darwin has been well aware of this fact, which is why I devoted considerable space to distinguishing the three different senses in which the evolutionary process might have a direction: uniformly, on averagc, or in the increase of various maxima. The fact of regressive evolution undermines only the first of these, which, so for as I know, no biologisc takes seriously anyway. (Nonetheless, cave fish are cool.)

Mysteriously, Romero interprets my essay as promulgating some sort of Lamarckian, orthogenetic vision of evolution. Bur the qualified conception of Evolutionary progress that I discussed sympathetically is essentially the same as that defended by Simpson (1949) and more rccently by Ayala (1988), neither of whom has been accused of harboring dark Lamarckian fantasies about evolution. I see no reason why my essay should cause consternation among the self-appointed custodians of Darwirian purity.

In what sense, then, is evolution "progressive"? As I made clear in my essay, a minirnal condition for evolutionary progress is that therc be at least some gradual directional changes in the history of life that embody improvement relative to some standard. This is an extremely modest conception of evolu. tionary progress, veering dangerously close to self-evident, and a far cry from some of the more grandiose proposals that have been advanced. Alas, with some topics no amount of careful explanation can preclude misunderstanding arising from adherence to deeply entrenched doctrines. I can only invite readers (and Romero) to read my essay with the intention to understand first, and to pass judgment second. Then a serious discussion can occur.

I conclude that debates over evolurionary progress have gone on long enough; but I doubt very much whether the end is in fact anywhere in sight.

\section{References cited}

Avin F, 1988. Can "progress" bc defined as a bio logical concept? Pages $75-96$ in Nireclo $M$, ed. Evolutionary Progross. Chicago: University of Chicago Press.

Dawkins R. 1999. The Exacnded Phenotype The long Reach of the Gene. Revised ectition. New York: Oxford University Press.

Maynard Smith I. 1970. Time in the evolutionary process. Studium Generale 23: 266-272.

Shanahan T. 2000. Evoiutionnry progress? Bioscience 50: 45]-459.

Sirnpson GG. 1949. The Meaning of Evolution. New Haven (NT): Yalc Universicy Press. 